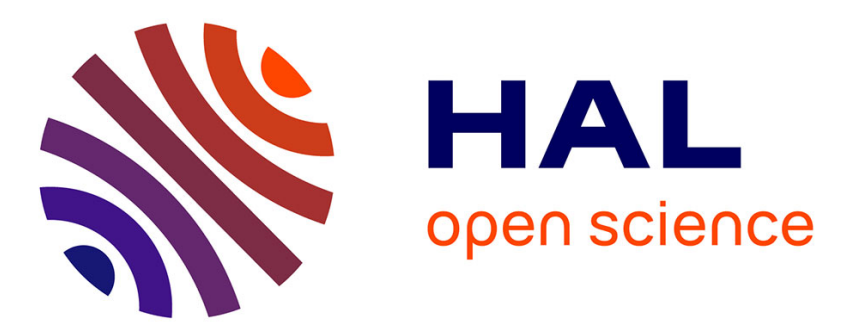

\title{
Incipient Offset Current Sensor Fault Detection and Diagnosis using Statistical Analysis and the Kullback Leibler Divergence for AC drive
}

Demba Diallo, Claude Delpha

\section{- To cite this version:}

Demba Diallo, Claude Delpha. Incipient Offset Current Sensor Fault Detection and Diagnosis using Statistical Analysis and the Kullback Leibler Divergence for AC drive. 43rd Annual Conference of the IEEE Industrial Electronics Society (IECON 2017), Oct 2017, Beijing, China. 10.1109/iecon.2017.8217416 . hal-01578467

\section{HAL Id: hal-01578467}

https://hal-centralesupelec.archives-ouvertes.fr/hal-01578467

Submitted on 12 Mar 2020

HAL is a multi-disciplinary open access archive for the deposit and dissemination of scientific research documents, whether they are published or not. The documents may come from teaching and research institutions in France or abroad, or from public or private research centers.
L'archive ouverte pluridisciplinaire HAL, est destinée au dépôt et à la diffusion de documents scientifiques de niveau recherche, publiés ou non, émanant des établissements d'enseignement et de recherche français ou étrangers, des laboratoires publics ou privés. 


\section{Incipient Offset Current Sensor Fault Detection and Diagnosis using Statistical Analysis and the Kullback Leibler Divergence for AC drive}

\author{
D. Diallo, IEEE, Senior Member \\ Group of Electrical Engineering of Paris, CNRS UMR 8507, \\ CentraleSupelec, Univ. Paris Sud, UPMC, ddiallo@,ieee.org
}

\begin{abstract}
In this paper, we propose line current sensor fault detection for AC drives. The method is based on the measured currents and the features are extracted either in the natural reference frame or in the transformed Park synchronous rotating frame. The features are the first four statistical moments or the Kullback Leibler Divergence (KLD) of the Probability Density Functions (PDF). For offset fault, we show that if the offset is higher than $3 \%$ of the current amplitude, the mean value is the most relevant value among the first four statistical moments that leads to good detection performances (low probability of false alarm and low probability of miss detection). But for incipient faults (offset ranging from 1 to $2 \%$ ), even the projection in the transformed Park reference frame cannot improve the fault detection. For these cases, we show that the fault information can be retrieved using the PDF and the KLD. This is confirmed by the results showing that the fault is detected with $\mathbf{1 0 0 \%}$ probability of detection.
\end{abstract}

Keywords: Current sensor fault, Fault Detection, statistical moments, Kullback-Leibler Divergence

\section{I- INTRODUCTION}

In every process, data are measured through sensors. In AC drives, the most usual sensors are current sensors, position or speed sensor, temperature sensor, voltage sensor, torque transducer and accelerometers.

Like other components, sensors can be affected by faults such as gain fault, offset or bias fault and noise. When the measured variables are used in closed loops, the controllers can be tuned to be robust against these perturbations. However when the fault becomes significant, the outputs of the controllers saturate and lead to a degradation of the performances e.g. oscillations in the DC bus voltage. Moreover for embedded applications the increase of the control voltages will increase the power consumption thereby reducing the vehicle autonomy.

Therefore health monitoring (fault detection and diagnosis) of sensors is required for condition based maintenance

\author{
C. Delpha, IEEE, Member \\ Laboratory of Signals and Systems, CNRS UMR 8506, \\ CentraleSupelec, Univ. Paris Sud, \\ claude.delpha@12s.centralesupelec.fr
}

or/and fault tolerance control using observers, estimators [1$6]$.

Following the general scheme described in figure 1 [7] for each of the four steps different approaches can be used.

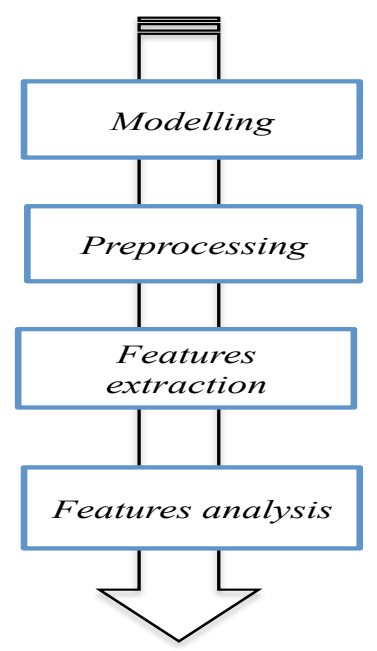

Fault Detection and Diagnosis

Fig. 1. Fault Detection and Diagnosis general scheme

The requirements for a fault detection and diagnosis method are summarized in figure 2 [8].

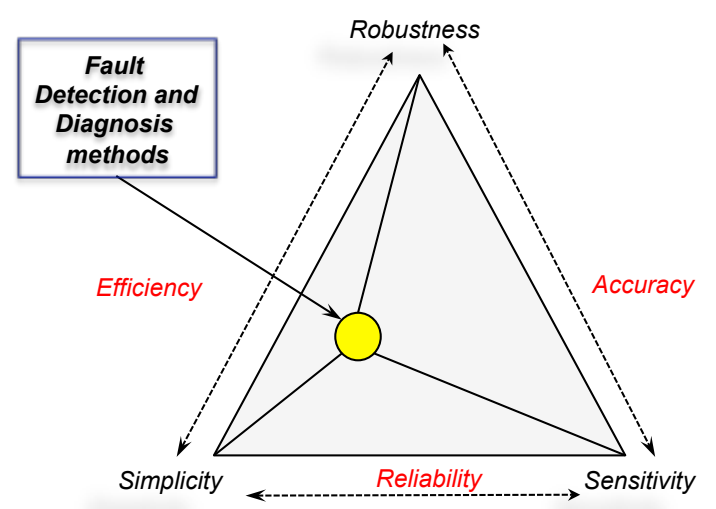

Fig. 2. Fault Detection and Diagnosis method requirements 
They are defined as follows:

- The simplicity that is defined as the amount of information for processing;

- The sensitivity that is defined as the capability of the method to detect a fault at its earliest stage;

- The robustness that measures the capability of the method to perform despite the perturbations.

- As it can be noticed, the selection of a method will be a compromise between:

The selection of a method is a compromise between these requirements.

Using a data-driven approach for the modelling, the current sensors fault diagnosis can be envisaged in the machine natural reference frame or in a transformed one (Concordia or Park) [9]

In this paper, we are interested in evaluating statistical moments as features for current sensor fault detection in the machine natural reference frame and in the Park rotating reference frame for different fault levels.

\section{CURRENT SENSOR FAULT MODELLING}

The most usual current sensor type used in AC drives is the active Hall Effect Sensor. From the actual current flowing in the machine winding to the current used in the digital control, the measured variable can be affected with different faults. The information can be lost (power outage of the sensor) degraded with an offset or a bias, a gain error or corrupted by significant noise.

Two faults will be envisaged for the current sensor: a bias or a gain fault as represented in figure 3 where $x$ is the actual variable and $x_{m}$ the measured one.

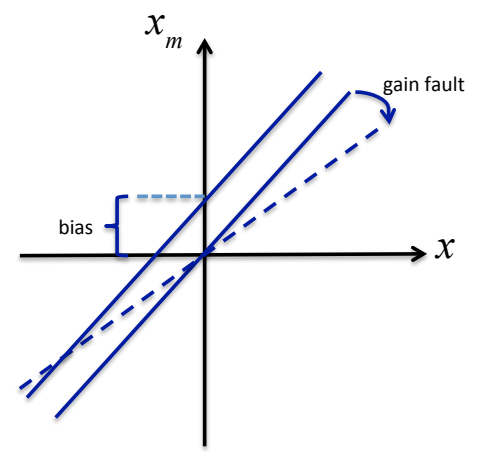

Fig. 3. Current sensor Fault types (bias and gain)

As a consequence, the current sensor fault can be modelled as the relation between the actual and the measured current with the following relation:

$\mathrm{I}_{\text {measured }}=(1+G) I_{\text {actual }}+\delta I_{\text {actual }}+\varepsilon$

where $\mathrm{G}$ is the gain error, $\delta I_{\text {actual }}$ is the offset and $\varepsilon$ is the noise.

In the natural $(a, b, c)$ frame, if we assume sinusoidal output currents, they can be expressed as :

$$
\begin{aligned}
& i_{a}=I \sin (\theta) \\
& i_{b}=I \sin (\theta-2 \pi / 3) \\
& i_{c}=I \sin (\theta-4 \pi / 3)
\end{aligned}
$$

\section{CURRENT SENSOR FAULT DETECTION}

\section{A. In the natural reference frame}

\section{1) Statistical Moments}

If we assume a random discrete variable $X=\left(x_{1}, \ldots, x_{j}, \ldots, x_{N}\right)$ of $\mathrm{N}$ samples, let us first recall the following definitions:

$\mu=\frac{1}{N} \sum_{1}^{N} x_{j}$ the mean value, measures the centre of the data distribution, $\sigma^{2}=\frac{1}{N} \sum_{1}^{N}\left(x_{j}-\mu\right)^{2}$ the variance measures the dispersion within the data dispersion, $S k w=\frac{1}{N} \sum_{1}^{N}\left(\frac{x_{j}-\mu}{\sigma}\right)^{3}$ the skewness measures the dissymetry of the data distribution and $K u r=\frac{1}{N} \sum_{1}^{N}\left(\frac{x_{j}-\mu}{\sigma}\right)^{4}$ the kurtosis measures the flatness of the data distribution.

\section{2) The Kullback Leibler Divergence}

For discrimination between two continuous probability distribution functions $f(x)$ and $g(x)$ of a random variable $\mathrm{x}$, the Kullback Leibler Information is defined as:

$$
I(f / / g)=\int f(x) \log \frac{f(x)}{g(x)} d x
$$

The divergence is the symmetric version of the Information and is given by [10]:

$K L D(f, g)=I(f / / g)+I(g / / f)$

Let us assume a three phase PMSM drive as displayed in figure 4 . The three currents are measured, as it is the case in sensitive applications (e.g. transportation).

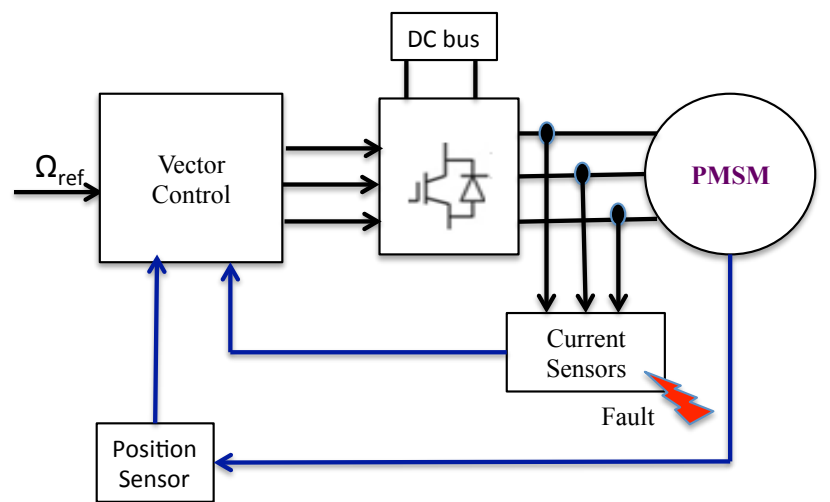

Fig. 4. Permanent Magnet Synchronous drive 
TABLE I.

MACHINE PARAMETERS

\begin{tabular}{ccc}
\hline \hline \multirow{2}{*}{ Symbol } & Quantity & Value and Unit \\
\hline$\Phi_{m}$ & Magnetic flux & $0.153 \mathrm{~Wb}$ \\
$L_{d}$ & D axis inductance & $3.5 \mathrm{mH}$ \\
$L_{q}$ & Q axis inductance & $4.5 \mathrm{mH}$ \\
$R_{s}$ & Resistance & $1.66 \Omega$ \\
$J$ & Inertia & $6^{*} 10^{-3} \mathrm{~kg} / \mathrm{m}^{2}$ \\
$f$ & Viscous friction & $0.5^{*} 10^{-3} \mathrm{Nm} / \mathrm{s}$ \\
$p$ & Pole pairs & 3 \\
$V_{n}$ & Nominal voltage & $200 \mathrm{~V}$ \\
$I_{n}$ & Nominal current & $6 \mathrm{~A}$
\end{tabular}

The flowchart of the methodology is displayed in figure 5 .

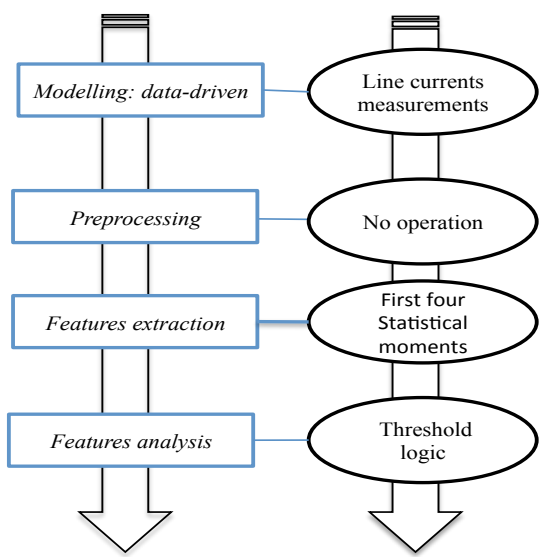

Fig. 5. Flowchart for the FDD of current sensor fault in the natural frame

\section{3) Offset fault}

In this section, an increasing offset from 1 to $10 \%$ is introduced in the phase a current measure.

The first four statistical moments are plotted for 100 realisations (the first 50 for the healthy case and last 500 for the faulty case).

As it can be seen in figure 6 , the mean value of the phase $a$ is a good fault indicator as soon as the offset is higher than $3 \%$.

This is confirmed with the ROC curve plotted in figure 7 for the three first offset faults. One can notice that for an offset fault of $3 \%$ the probability of detection (PD) is almost $100 \%$ and the probability of false alarm (PFA) is null.

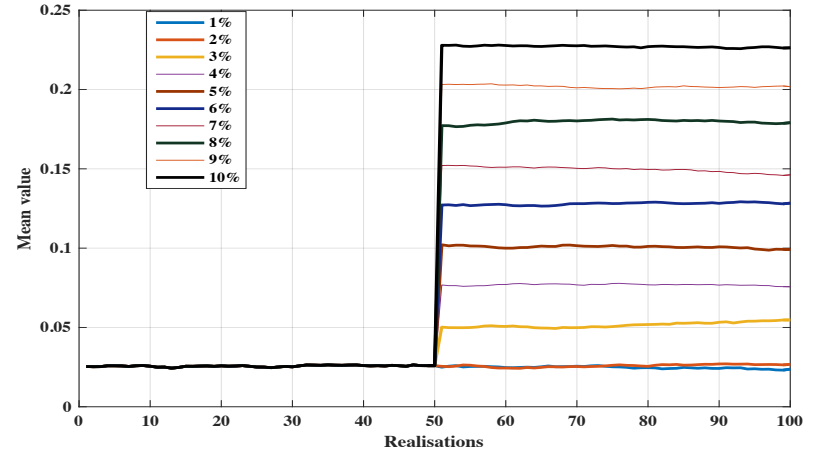

Fig. 6. Mean value of the current in phase a

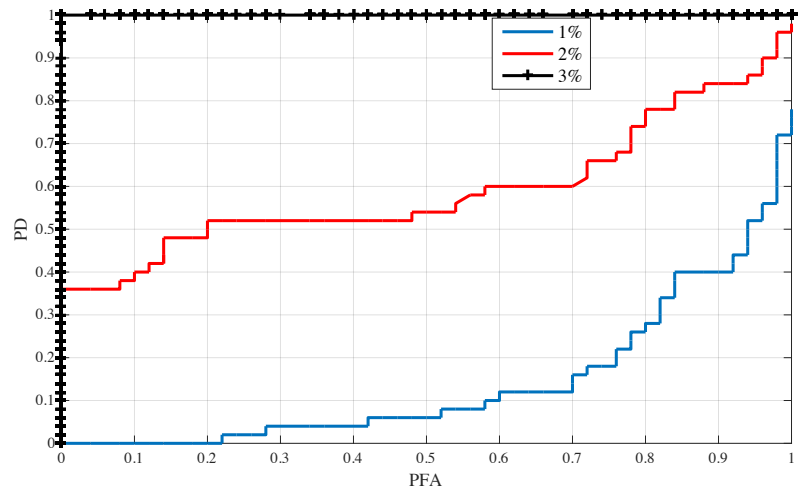

Fig. 7. ROC curve for the mean value of the current in phase a

Because of the isolated neutral of the machine, the same conclusions can be drawn for the other two phases when analysing the mean values.

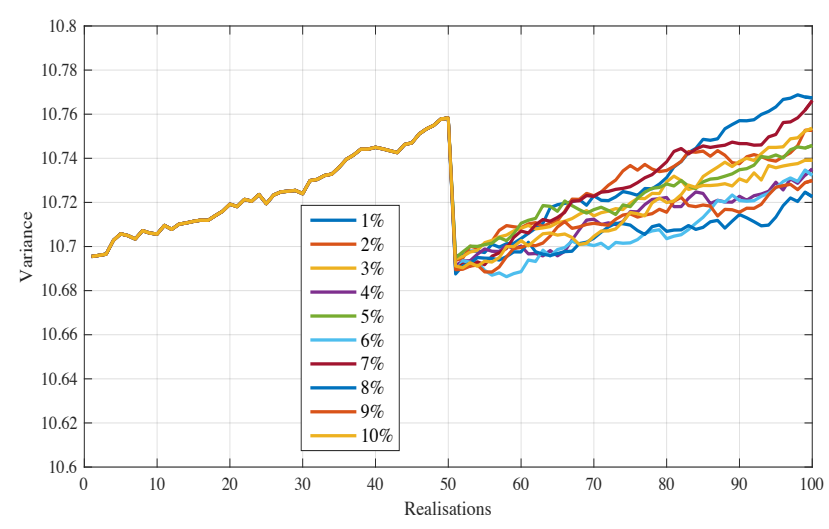

a) Variance

Looking at the other statistical moments plotted in figure 8 confirms that there is no significant variation of the variance, the skewness and the kurtosis even for fault levels higher than $3 \%$. 


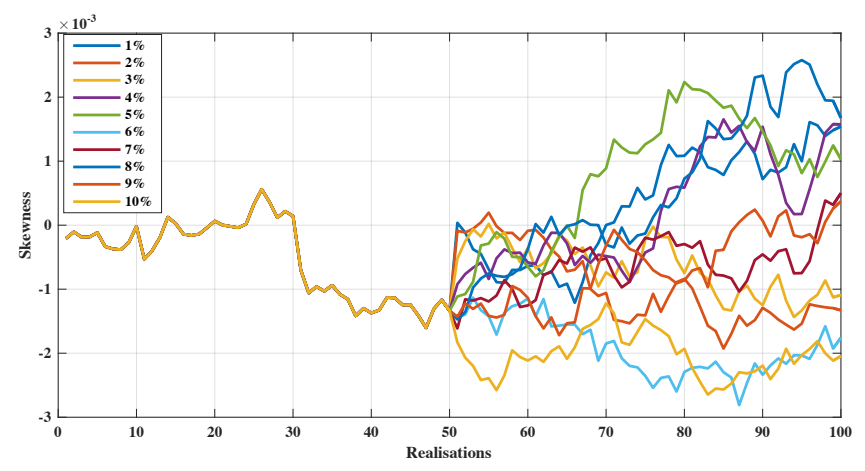

b) Skewness

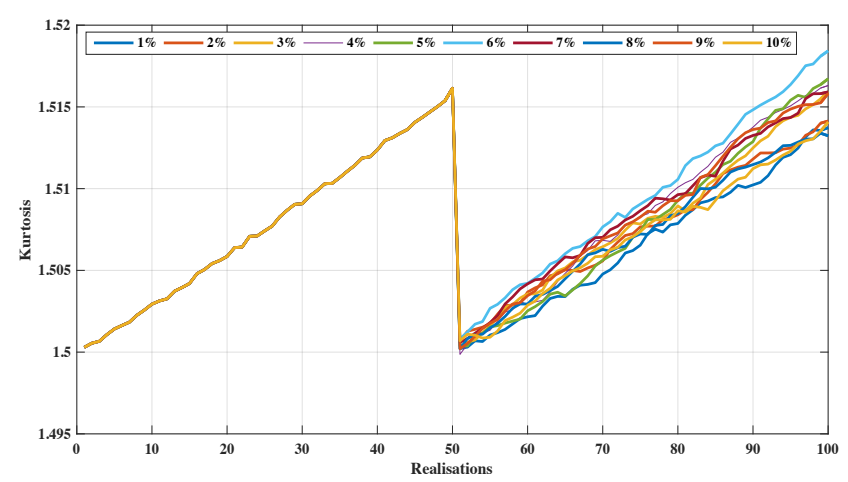

c) Kurtosis

Fig. 8. Phase a current statistical properties

In order to compare their efficiency a sensitivity index is computed as follows:

Sensitivity $=\frac{\left\langle C_{r}\right\rangle_{\text {faulty }}-\left\langle C_{r}\right\rangle_{\text {healthy }}}{\left.\operatorname{Max}\left(C_{r}-<C_{r}\right\rangle\right)_{\text {healthy }}}$

where $C_{r}$ stands for the mean value, the variance, the skewness or the kurtosis and $\left\langle C_{r}\right\rangle$ is the mean value [7].

From its definition, one can retrieve the following conclusions:

- if $1<$ Sensitivity $<0.5,0.5<P_{M D}<1$

- if Sensitivity $=1, P_{M D}=0.5$

- if Sensitivity $>2, P_{M D}=0$

where $P_{M D}$ is the probability of miss detection.

The sensitivity of the four criteria is plotted in figure 9 and confirms that the most sensitive is the mean value.

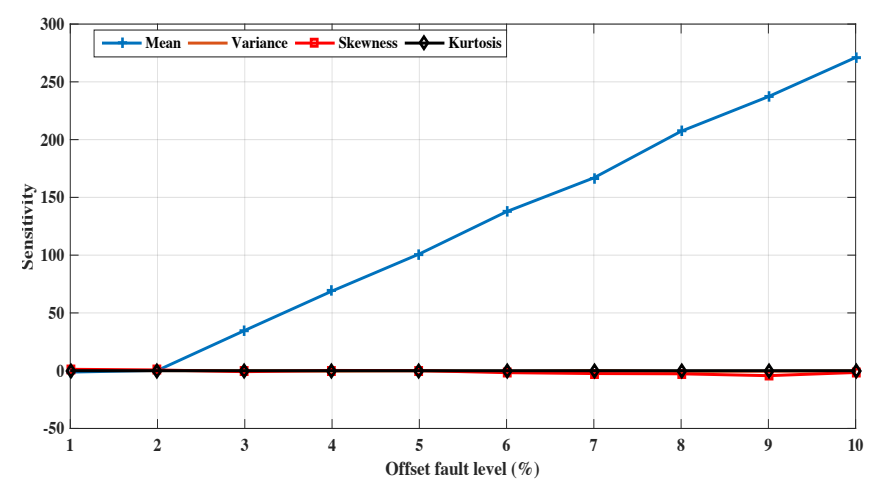

Fig. 9. Sensitivity index for the current in phase a

\section{$B$. In the transformed Park reference frame}

The flowchart is depicted in figure 10 .

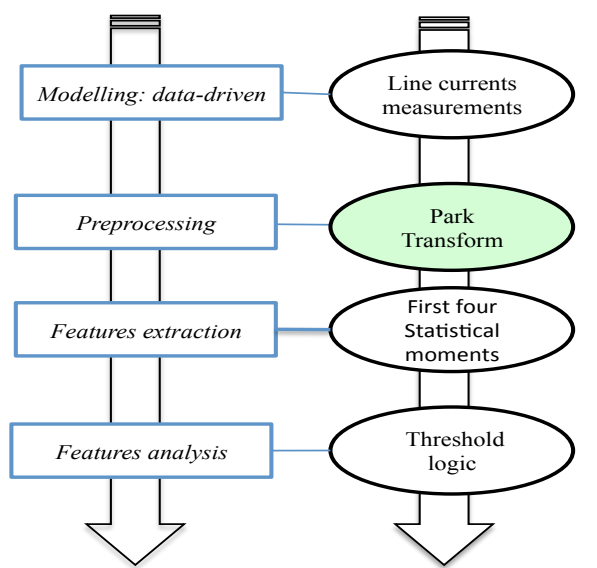

Fig. 10. Flowchart for the FDD of current sensor fault in the Park reference frame

Following the Park transform, the currents $\left(i_{d}, i_{q}, i_{0}\right)$ in healthy conditions are DC variables:

$i_{d h}=0$

$i_{q h}=\sqrt{\frac{3}{2}} I$

$i_{0 h}=0$

In the following, the homopolar component $\mathrm{i}_{0}$ will no longer be considered even it may contain relevant information. Only the $\mathrm{d}$ and q currents will be studied.

In case of gain fault $(G \neq 0)$, the transformed currents become:

$$
\begin{aligned}
& i_{d f}=i_{d h}+\frac{1}{\sqrt{6}} G I \sin (2 v)+\zeta \\
& i_{q f}=i_{q h}-\frac{1}{\sqrt{6}} G I(1+\cos (2 v))+\zeta
\end{aligned}
$$

In case of offset fault, the transformed currents are: 
$i_{d f}=i_{d h}+\sqrt{\frac{2}{3}} \delta I \cos (v)+\zeta$

$i_{q f}=i_{q h}-\sqrt{\frac{2}{3}} \delta I \sin (v)+\zeta$

where $\zeta$ is the noise and $v=\theta, \theta-\pi / 3, \theta-2 \pi / 3$ depending of which phase is corrupted.

For the same offset fault range $(1 \%$ to $10 \%)$, the mean value, the variance, the skewness and the kurtosis of the torque current $i_{q}$ are plotted in Fig. 11. Because of the current controllers, the evolution is non monotonic as it could have been derived from the analysis of (5).

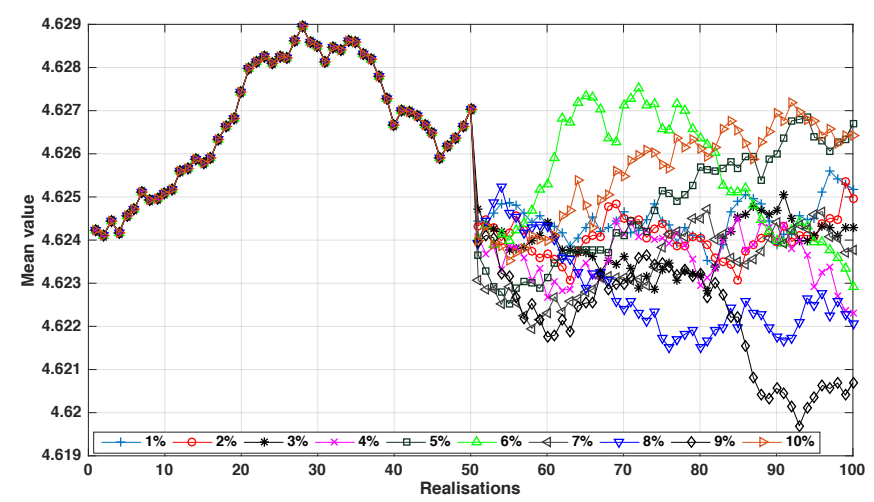

a) Mean value

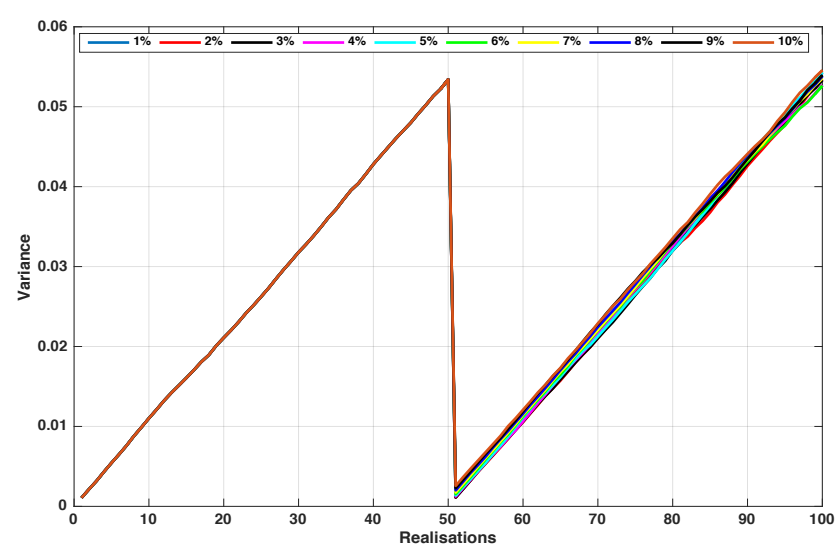

b) Variance

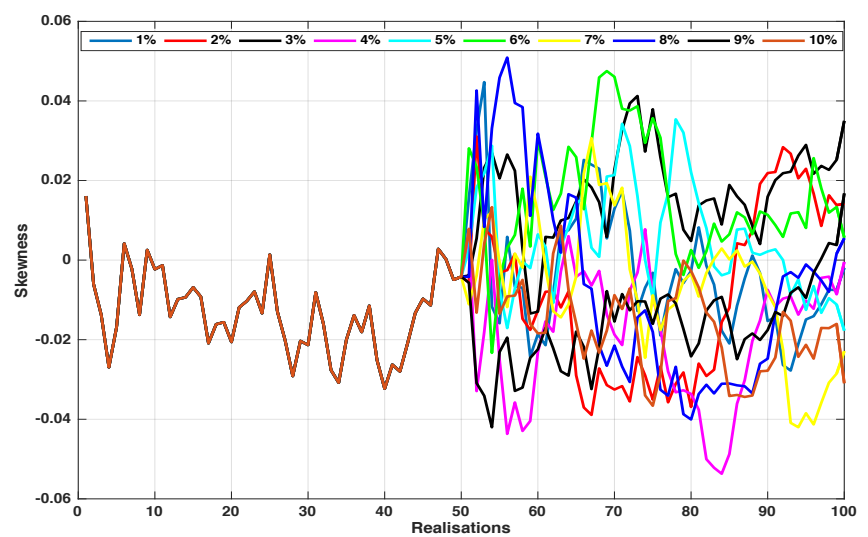

c) Skewness

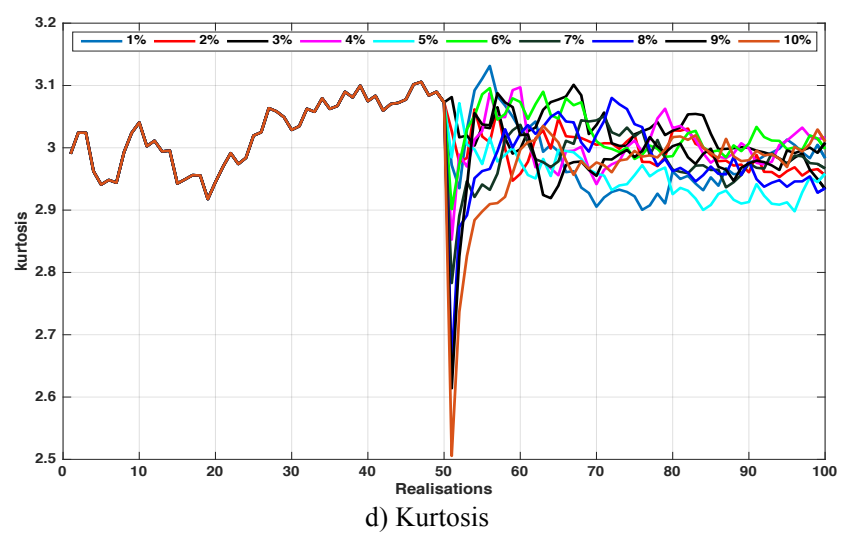

Fig. 11. First four statistical moments of the $i_{q}$ current

The sensitivity criteria are computed for all the first four statistical moments are displayed in Fig. 12.

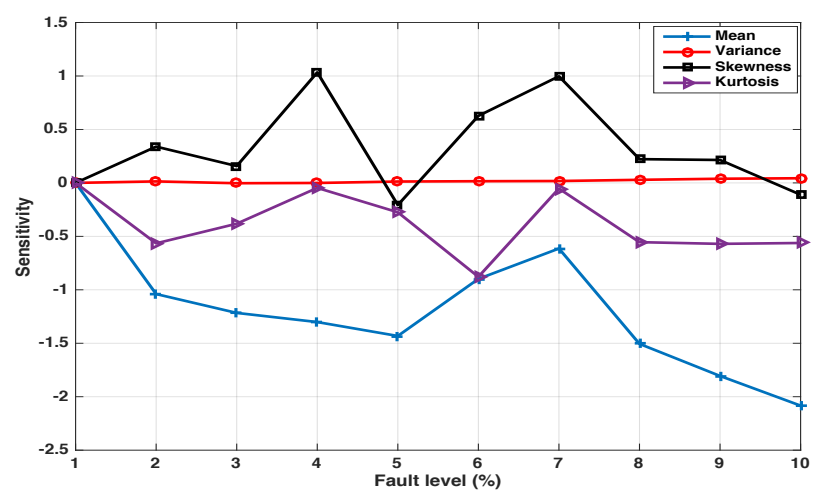

Fig. 12. Sensitivity criteria for the $i_{q}$ current

For all the four moments, the absolute value of the sensitivity criteria is $\leq 2$ (except for the mean value when the fault severity is $10 \%$ ), which means that the probability of miss detection $P_{M D}>0$.

The variance has a very low sensitivity with a corresponding $P_{M D}>50 \%$. The mean value and the skewness have the higher sensitivity to the offset fault. However even for the mean value, for the lowest fault levels ( 1 to $3 \%$ ), the fault detection performances are very poor with a probability of miss detection $P_{M D} \approx 0.5$. And the situation is worse with the skewness because its sensitivity is lower than 0.5 meaning that the $P_{M D} \approx 1$.

Even if the controllers can mitigate the fault very low severity (incipient fault), for efficient condition-based maintenance, it is desirable to address this issue.

\section{INCIPIENT CURRENT SENSOR FAULT DETECTION USING KULLBACK LEIBLER DIVERGENCE}

In the former paragraph, we have shown that for incipient fault meaning the fault level is lower than $3 \%$, none of the four statistical moments can be used as reliable 
fault detection feature. For these lower fault levels, while the Signal to Noise Ratio (SNR) is equal to $40 \mathrm{~dB}$, the Fault to Noise Ratio (FNR) is $-10.3 \mathrm{~dB}$ for $1 \%$ fault and $-4.3 \mathrm{~dB}$ for $2 \%$. If the noise level is higher ( SNR $<40 \mathrm{~dB}$ ), the FNR will be lower and the fault detection more tricky.

Therefore it's obvious that another feature is required to perform reliable incipient fault detection.

The Kullback Leibler Divergence (KLD) has shown its superiority for detecting incipient fault [11]. This divergence has been proved to be an upper bound to several distance measures [12].

The corresponding flowchart is displayed in figure 13 .

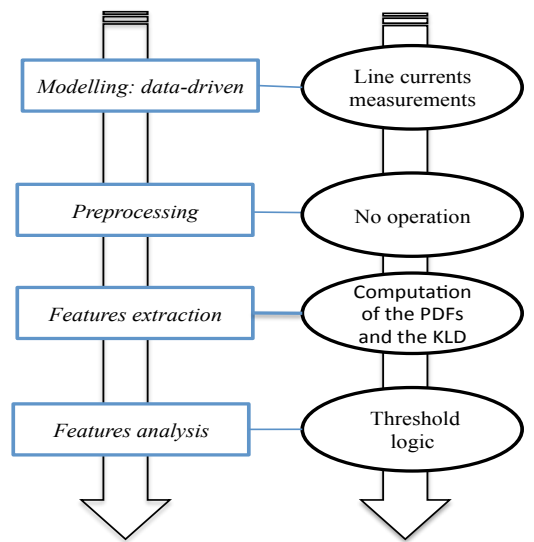

Fig. 13. Flowchart for the FDD of current sensor fault in the natural reference frame using the KLD

For these two fault levels, after the computation of the Probability Density Functions (PDF), the KLD is plotted in figure 14. The first 60 realizations are for the healthy case while the last 60 ones are for the faulty cases. Despite the fault effect is not severe, there is still a significant variation of the KLD that allows the fault detection at its early occurrence.

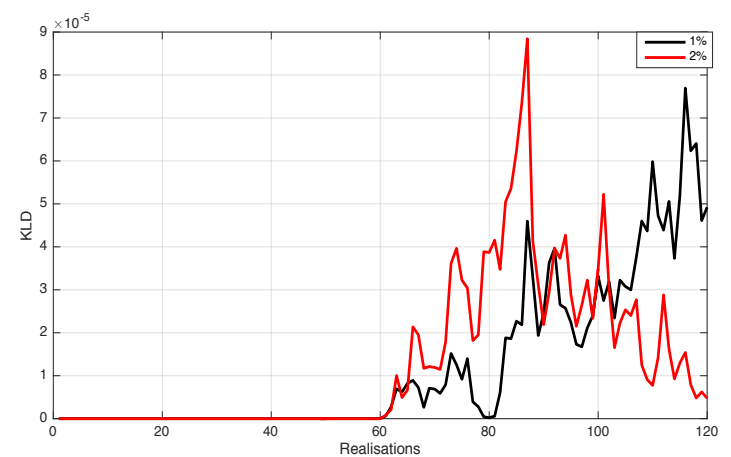

Fig. 14. KLD of the current $i_{a}$ for the two incipient fault levels

The sensitivity criteria are respectively 15.7 and 48.5 for the two fault levels. This means that the $P_{M D}$ is null.

\section{CONCLUSION}

In this paper, we have proposed line current sensor fault detection using the measured currents either in the natural reference frame or in the transformed Park synchronous rotating frame in an $\mathrm{AC}$ drive. We have shown that if the offset fault is higher than $3 \%$, the mean value is the most relevant value among the first four statistical moments in order to have good detection performances (low probability of false alarm and low probability of miss detection). But for incipient faults (offset ranging from 1 to $2 \%$ ), even the projection in the transformed Park reference frame (with continuous variables) cannot improve the fault detection. We show that the fault information can be retrieved using the PDF and the Kullback Leibler Divergence (KLD). The results confirm the fault detection with $100 \%$ probability of detection.

\section{REFERENCES}

[1] D. Diallo; M.E.H Benbouzid; M.A Masrur, "Special Section on Condition Monitoring and Fault Accommodation in Electric and Hybrid Propulsion Systems," IEEE Transactions on Vehicular Technology, vol.62, no.3, pp.962-964, March 2013, doi: 10.1109/TVT.2013.224573

[2] Campos-Delgado, D. U., Espinoza-Trejo, D. R., Palacios, E. "Faulttolerant control in variable speed drives: a survey". IET, Electric Power Applications, vol.2, no.2, pp.121-134, 2008

[3] Lee B., Jeon N., Lee H. "Current sensor fault detection and isolation of the driving motor for an in-wheel motor drive vehicle“. International conference on Control, Automation and Systems (ICCAS), vol., no., pp.486, 491, 26-29 Oct 2011

[4] Rothenhagen, K., F. Fuchs W. "Current Sensor Fault Detection, Isolation, and Reconfiguration for Doubly Fed Induction Generators“ IEEE Transactions on Industrial Electronics, vol.56, no.10, pp.42394245, 2009.

[5] Najafabadi T., Salmasi F., Jabehdar-Maralani P. "Detection and Isolation of Speed-, DC-Link Voltage and Current-Sensor Faults Based on an Adaptive Observer in Induction-Motor Drives“, IEEE Transactions on Industrial Electronics, vol. 58, no. 5, 2011.

[6] Nuno M. A. Freire, Estima J., Cardoso A. J. M. "New Approach for Current Sensor Fault Diagnosis in PMSG Drives for Wind Energy Conversion Systems", IEEE Transactions on Industry Applications, pp. 1206-1214, 2014.

[7] J. Harmouche, C. Delpha, D. Diallo, Y. Le Bihan “ Statistical approach for non-destructive incipient damage detection and characterisation using Kullback Leibler Divergence," IEEE Transactions on Reliability, Year: 2016, Volume: 65, Issue: 3, Pages: $1360-1368$

[8] C. Delpha, D. Diallo ; "Incipient Fault Detection and Diagnosis : a Hidden Information Detection Problem," IEEE ISIE 2015, Conference Proceedings, Buzios, Rio de Janeiro, Brazil

[9] D. Diallo, C. Delpha, S. Diao" Current sensor fault estimation in the (d,q) rotating synchronous frame, ", IECON 2016 - 42nd Annual Conference of the IEEE Industrial Electronics Society, Year: 2016, Pages: 6323 - 6328, DOI: 10.1109/IECON.2016.7793494, 24-27 OctFlorence, Italy

[10] M. Basseville, V. I. Nikiforov; Detection of Abrupt Changes Theory and Application, published by Prentice-Hall, Inc. (ISBN 0-13126780-9 - April 1993 - Englewood Cliffs, N.J.)

[11] J. Harmouche, C. Delpha, D. Diallo; "Incipient Fault Detection and Diagnosis Based on Kullback Leibler Divergence Using Principal Component Analysis: Part I, "Signal Processing, Elsevier, Vol. 94, January 2014, pp. 278-287

[12] G.T. Toussaint, "Some inequalities between distance measures for feature evaluation", IEEE Transactions on Computers, C-21 (4), 1972, pp. $409-410$ 